\title{
Impact of Wall Materials on Physico-Chemical Properties and Stability of Eggplant Peels Anthocyanin Hydrogels
}

\author{
Nina-Nicoleta Condurache (Lazăr) ${ }^{1} \oplus$, Mihaela Turturică ${ }^{1}$, Elena Enachi ${ }^{1} \mathbb{1}$, Vasilica Barbu ${ }^{1}($, \\ Gabriela-Elena Bahrim ${ }^{1}{ }^{1}$, Nicoleta Stănciuc ${ }^{1}$, Constantin Croitoru ${ }^{2}$ and Gabriela Râpeanu ${ }^{1, *}$ \\ 1 Faculty of Food Science and Engineering, Dunărea de Jos University of Galati, Domnească Street 111, \\ 800201 Galati, Romania; nina.condurache@ugal.ro (N.-N.C.); mihaela.turturica@ugal.ro (M.T.); \\ elena.ionita@ugal.ro (E.E.); vasilica.barbu@ugal.ro (V.B.); gabriela.bahrim@ugal.ro (G.-E.B.); \\ nicoleta.stanciuc@ugal.ro (N.S.) \\ 2 Academy of Agricultural and Forestry Sciences, 61 Marasti Blvd, 011464 Bucharest, Romania; \\ c.croitoru@sodinal.com \\ * Correspondence: gabriela.rapeanu@ugal.ro; Tel.: +40-336-130-177
}

check for updates

Citation: Condurache, N.-N.; Turturică, M.; Enachi, E.; Barbu, V.; Bahrim, G.-E.; Stănciuc, N.; Croitoru, C.; Râpeanu, G. Impact of Wall Materials on Physico-Chemical Properties and Stability of Eggplant Peels Anthocyanin Hydrogels. Inventions 2021, 6, 47. https:// doi.org/10.3390/inventions6030047

Academic Editor: Farid Chemat

Received: 10 June 2021

Accepted: 28 June 2021

Published: 29 June 2021

Publisher's Note: MDPI stays neutral with regard to jurisdictional claims in published maps and institutional affiliations.

Copyright: (c) 2021 by the authors. Licensee MDPI, Basel, Switzerland. This article is an open access article distributed under the terms and conditions of the Creative Commons Attribution (CC BY) license (https:/ / creativecommons.org/licenses/by/ $4.0 /)$.

\begin{abstract}
In this study, eggplant peel extract was used to obtain hydrogels. Two experimental variants were realized by varying the wall materials. Whey proteins isolate (WPI), citrus pectin $(\mathrm{P})$, and sodium carboxymethylcellulose $(\mathrm{CMCNa})$ were used as wall materials. The microcapsules were obtained by the gelation technique, followed by freeze-drying in order to obtain powders. Both experimental variants were analyzed in terms of phytochemical content, antioxidant activity, storage stability, and in vitro digestibility. Additionally, confocal microscopy was used to observe the encapsulation of the bioactive compounds from the eggplant peel extract into the selected matrices. The encapsulation efficiency of the powders varied from $64.67 \pm 0.68 \%$ for variant 1 (V1) to $96.44 \pm 3.43 \%$ for variant 2 (V2). Both powders presented high bioactive compound content with high antioxidant activity. V2 showed the highest stability within 28 days of storage, but also in the simulated digestive system.
\end{abstract}

Keywords: eggplant peels; bioactive compounds; hydrogels; anthocyanins

\section{Introduction}

The agro-food industries generate annually overwhelming amounts of wastes by the processing of various vegetables and fruits [1]. Until a few years ago, food waste disposal was not a matter of concern. However, the increasing amounts of waste generated and the environmental issues caused by them have drawn attention. Currently, various organizations around the world are trying to find solutions to minimize food wastes with lower economic costs [2]. Due to the high content of proteins, lipids, sugars, fibers, pectin, or phytochemical compounds, the food wastes can be the ideal source from which value-added foods can be obtained for feeding the growing population. Their valorization in value-added food products represents an advantageous way of managing the wastes problems, turning them from wastes into by-products [1,2].

The fruit and vegetable processing industry generates by-products especially rich in natural antioxidants, such as polyphenols. These compounds are appreciated for their nutritional and functional properties. A regular intake of phenolic compounds appears to reduce the risk for developing coronary heart disease, hypertension, diabetes, obesity, gastrointestinal diseases, etc. [3]. Their antioxidant activity delays the formation of offflavors and rancidity in food products, making them the perfect natural preservatives. They can also be used as natural pigments for food and beverage coloring or in cosmetics and nutraceuticals [4].

Aubergine, or eggplant, the name under which it is known worldwide, is a nontuberous Solanaceae family vegetable. Solanum melongena is a tropical fruit with multiple 
shapes, sizes, and colors, and is very perishable yet very tasty. The most commercially important one is the purple variety (Solanum melongena $\mathrm{L}$.) due to the anthocyanins located in the peels [5].

The anthocyanins are flavonoids with red, blue, and purple colors in fruits, vegetables, and flowers. Their basic structure is composed of a flavylium cation to which different sugars, hydroxyl or methoxyl groups are attached [6]. Of all the phenolic compounds, anthocyanins are the most sensitive. They easily degrade at higher $\mathrm{pH}$, temperatures, or at prolonged exposure to light, oxygen, enzymes, etc. [7]. The anthocyanins are also sensitive to the digestive system conditions, especially when consumed separately from the original food matrix, with only $1-2 \%$ of the ingested amount being absorbed [8]. The latest researches propose encapsulation as a method of increasing the bioavailability and bioaccessibility of anthocyanins. When choosing the suitable encapsulation method, the properties of the bioactive compound, encapsulating material, and desired final product must be taken into account [9].

The present study aimed to obtain functional ingredients from eggplant peels bioactives for food or nutraceuticals applications. To extract the phenolic compounds from the eggplant peels, the ultrasound-assisted extraction (UAE) method was applied. The extract was characterized in terms of phytochemical content and antioxidant activity. Further, the extract was used for encapsulation by the gelation technique, followed by freeze-drying in order to obtain powders. Sodium carboxymethylcellulose $(\mathrm{CMCNa})$, pectin $(\mathrm{P})$, and whey protein isolate (WPI) were used as wall materials in different concentrations due to their ability to form hydrogels with three-dimensional networks. The two experimental variants resulting were analyzed in terms of encapsulation efficiency (EE), total anthocyanin content (TAC), total flavonoid content (TFC), total polyphenol content (TPC), and antioxidant activity. The microstructure of the powders was analyzed by confocal scanning laser microscopy (CLSM). The evolution of phytochemicals during the storage stability test was also monitored for 28 days. The in vitro release profile of the TAC and antioxidant activity under simulated gastric and intestinal juices was also performed.

\section{Materials and Methods}

\subsection{Materials}

Whey protein isolate (protein content of 95\%) from Fonterra (New Zeeland). Ethanol 96\% (EtOH) from Titolchimica (Italy). HPLC purity methanol (MeOH), 2,2-diphenyl1picrylhydrazyl (DPPH), glacial acetic acid $\left(\mathrm{CH}_{3} \mathrm{COOH}\right)$, sodium nitrite solution $\left(\mathrm{NaNO}_{2}\right)$, potassium chloride solution $(\mathrm{KCl})$, sodium acetate solution $\left(\mathrm{CH}_{3} \mathrm{COONa}\right)$, aluminum chloride $\left(\mathrm{AlCl}_{3}\right)$, sodium hydroxide $(\mathrm{NaOH})$, sodium carbonate $\left(\mathrm{Na}_{2} \mathrm{CO}_{3}\right)$, apple pectin, sodium carboxymethyl cellulose (CMCNa), 6-hydroxy-2,5,7,8-tetramethylchromane-2carboxylic acid (Trolox), Folin-Ciocâlteu reagent, gallic acid, hydrochloric acid $(\mathrm{HCl})$, sodium bicarbonate $\left(\mathrm{NaHCO}_{3}\right)$, Trizma buffer, the standards used for the HPLC analysis, delphinidin 3-O-glucoside, delphinidin 3-O-rutinoside, and cyanidin 3-O-rutinoside were obtained from Sigma-Aldrich Steinheim, Germany.

\subsection{Methods}

\subsubsection{Biologically Active Compounds Extraction}

The Solanum melongena L. autochthonous variety fruits were purchased from a local market in Galați, Romania. The purple outer layer of the fruit were peeled in uniform strips, washed with ultrapure water, dried with paper towels, and frozen. Subsequently, the peels were freeze-dried until $90 \%$ dry weight $(\mathrm{dw})$, at $-42{ }^{\circ} \mathrm{C}$, under a pressure of $0.10 \mathrm{mBar}$, with a CHRIST Alpha 1-4 LD plus equipment (Germany) for $48 \mathrm{~h}$.

The biologically active compounds were extracted using the UAE method described by Condurache et al. [10]. Briefly, $1 \mathrm{~g}$ of freeze-dried eggplant peels was mixed with $15 \mathrm{~mL}$ of a solvent mixture composed of $\mathrm{EtOH} 96 \%$ and glacial acetic acid, in a 4:1 ratio. The mixture was exposed for $15 \mathrm{~min}$ to ultrasounds at a $40 \mathrm{kHz}$ frequency and $25{ }^{\circ} \mathrm{C}$ on a Smart sonic cleaner ultrasonic bath (MRC. LTD, Holon, Israel). Further, the extracts were 
centrifuged for $10 \mathrm{~min}$ at $14,000 \mathrm{rpm}$ and $4{ }^{\circ} \mathrm{C}$. The resulting supernatant was concentrated to dryness under reduced pressure at $40^{\circ} \mathrm{C}$ (AVC 2-18, Christ, Shropshire, UK), and finally phytochemically analyzed.

\subsubsection{Extract Characterization}

The extract was characterized in terms of yield of extraction, TAC, TFC, TPC, and antioxidant activity, as described by Turturică et al. [11]. In brief, the TACs of $10 \mathrm{mg} / \mathrm{mL}$ eggplant peels' extract in ultrapure water were quantified using the $\mathrm{pH}$ differential method, and the results were expressed as mg delphinidin 3-O-glucoside (D3G)/g dw [11]. The TFC was analyzed using the colorimetric method based on the capacity of $\mathrm{AlCl}_{3}$ to form stable complexes with the flavones or flavonols. The results were expressed as $\mathrm{mg}$ catechin equivalent (CE)/g dw [11]. The TPCs were quantified using the colorimetric method with the Folin-Ciocâlteu reagent, and the results were expressed as mg gallic acid equivalents (GAE)/g dw [11]. The free radical scavenging activity of the extract was measured using the DPPH, and the results were expressed as $\mathrm{mM}$ trolox equivalents (TE)/g dw [11]. The yield of extraction was calculated using formula (1) as described by Swer et al. [12]:

$$
\mathrm{EY}=\frac{\text { extract weight }}{\text { eggplant peels weight }} \times 100
$$

\subsubsection{HPLC Analysis of the Anthocyanins}

The chromatographic analysis of the anthocyanins found in eggplants, including separation, identification, and quantification, was made by the slightly modified method described by Turturica et al. [11]. The used HPLC system was a Thermo Finnigan Surveyor containing a diode array detector and Xcalibur software (Finnigan Surveyor LC, Thermo Scientific, Waltham, MA, USA). The volume used for the injection of the samples was $20 \mu \mathrm{L}$ with a flow rate of $1.0 \mathrm{~mL} / \mathrm{min}$. Before the injection, the samples were filtered using $0.22 \mu \mathrm{m}$ syringe filters. All standard compounds used in this study were acquired from Sigma-Aldrich (Darmstadt, Germany) and were of high purity $(>95.0 \%)$.

\subsubsection{Encapsulation of the Biologically Active Compounds from the Eggplant Peel Extract}

The biologically active compounds from the eggplant peels' extract were encapsulated in hydrogels using the method described by Serrano-Cruz et al. [13] with slight modifications. The hydrogels are 3D networks made from polymeric chains cross-linked by physical or chemical bonds, having a high affinity for water [14]. In our study, two experimental variants were obtained using CMCNa, P, and WPI as wall material. For the first variant (V1), 1.5\% P, 1.5\% CMCNa, and 3\% WPI were dispersed in ultrapure water during the agitation on a magnetic stirrer (IKA RCT Basic, Staufen Germany) for $6 \mathrm{~h}$ at $45^{\circ} \mathrm{C}$ and $450 \mathrm{rpm}$. For the second variant (V2), 2.25\% P, 2.25\% CMCNa, and 1.5\% WPI in ultrapure water were also hydrated for $6 \mathrm{~h}$ at $45^{\circ} \mathrm{C}$ and $450 \mathrm{rpm}$ on the heating magnetic stirrer (Figure 1). Both variants were allowed to stand at $4{ }^{\circ} \mathrm{C}$ overnight to ensure the full hydration of the wall materials, after which $25 \mathrm{mg} / \mathrm{mL}$ of extract was added in each mixture and homogenized for $2 \mathrm{~h}$ at $25^{\circ} \mathrm{C}$ and $450 \mathrm{rpm}$. The measured $\mathrm{pH}$ of the mixtures was 2.5 due to the extract. The samples were frozen at $-80{ }^{\circ} \mathrm{C}$. Further, the mixtures were freeze-dried to obtain stable powders with a Alpha 1-4 LD plus equipment (CHRIST, Osterode am Harz, Germany) for $48 \mathrm{~h}$, at $-42{ }^{\circ} \mathrm{C}$ under a pressure of $0.10 \mathrm{mBar}$ until a $94.37 \%$ dw for V1 and $96.31 \%$ dw for V2. Finally, the powders were collected and packed in plastic tubes with light protection and stored at $4{ }^{\circ} \mathrm{C}$ for later analyses. 
V1

$100 \mathrm{~mL}$ ultrapure water

$+1.5 \% \mathrm{P}$

$+1.5 \% \mathrm{CMCNa}$

$+3 \% \mathrm{WPI}$

$\downarrow$

Solubilization $6 \mathrm{~h}, 45^{\circ} \mathrm{C}, 450 \mathrm{rpm}$

Overnight rest, $4^{\circ} \mathrm{C}$, dark

$+25 \mathrm{mg} / \mathrm{mL}$ eggplant peel extract

Solubilization $2 \mathrm{~h}, 25^{\circ} \mathrm{C}, 450 \mathrm{rpm}$

Freezing $-80^{\circ} \mathrm{C}$

Freeze-drying $48 \mathrm{~h},-42{ }^{\circ} \mathrm{C}, 0.10 \mathrm{mBar}$ pressure, $94.37 \% \mathrm{dw}$.
V2

$100 \mathrm{~mL}$ ultrapure water

$+2.25 \% \mathrm{P}$

$+2.25 \% \mathrm{CMCNa}$

$+1.5 \% \mathrm{WPI}$

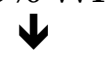

Solubilization $6 \mathrm{~h}, 45^{\circ} \mathrm{C}, 450 \mathrm{rpm}$
$\downarrow$
Overnight rest, $4{ }^{\circ} \mathrm{C}$, dark
$\downarrow$
$+25 \mathrm{mg} / \mathrm{mL}$ eggplant peel extract
$\downarrow$
Solubilization $2 \mathrm{~h}, 25^{\circ} \mathrm{C}, 450 \mathrm{rpm}$
$\downarrow$
Freezing $\underset{\Downarrow}{\downarrow}-80^{\circ} \mathrm{C}$

Freeze-drying $48 \mathrm{~h},-42{ }^{\circ} \mathrm{C}, 0.10 \mathrm{mBar}$

pressure, $96.31 \% \mathrm{dw}$.

Figure 1. The eggplant peel extract encapsulation scheme using the gelation technique.

\subsubsection{Powder Characterization}

The obtained powders were phytochemically analyzed in terms of initial TAC, TFC, TPC, and antioxidant activity [11]. The encapsulation efficiency (EE) of the anthocyanins was also calculated by measuring the TAC and the surface anthocyanins content (SAC) as described by Condurache et al. [15].

To measure the TAC, TFC, TPC, and antioxidant activity, $200 \mathrm{mg}$ of each powder was mixed with $7 \mathrm{~mL}$ of methanol/glacial acetic acid/distilled water (25:4:21 v/v/v). The mixtures were vortexed for $1 \mathrm{~min}$ and sonicated for $30 \mathrm{~min}$ at $25{ }^{\circ} \mathrm{C}$ and $40 \mathrm{kHz}$ using an ultrasonic bath (MRC. LTD, Holon, Israel). Further, the samples were centrifuged at $14,000 \mathrm{rpm}$ for $10 \mathrm{~min}$ at $4{ }^{\circ} \mathrm{C}$, and the supernatant was analyzed.

The EE represents the content of anthocyanins encapsulated in the matrix, and it was calculated as a percentage ratio between TAC and surface anthocyanin content (SAC). The SAC was measured by mixing $200 \mathrm{mg}$ of each powder with $7 \mathrm{~mL}$ of ethanol/methanol (1:1 $v / v$ ), vortexing for $1 \mathrm{~min}$, and centrifuging at $14,000 \mathrm{rpm}$ for $10 \mathrm{~min}$ at $4{ }^{\circ} \mathrm{C}$. The resulting supernatants were analyzed using the $\mathrm{pH}$ differential method [11]. The EE was calculated using Equation (2).

$$
\% \mathrm{EE}=\frac{(\mathrm{TAC}-\mathrm{SAC})}{\mathrm{TAC}} \times 100
$$

TAC—Total Anthocyanin Content; SAC—Surface Anthocyanin Content.

\subsubsection{Storage Stability}

The encapsulated powders were evaluated regarding the TAC, TFC, TPC, and antioxidant activity during storage at room temperature in plastic tubes with light protection. The biologically active compounds were extracted as described in Section 2.2.5. Powder characterization and the phytochemicals were analyzed after 28 days of storage.

\subsubsection{Confocal Laser Scanning Microscopy (CLSM)}

The Confocal Laser Scanning Microscopy technique was used to observe the encapsulation process of the eggplant peel extracts' bioactives within the selected matrices. As an analysis method, confocal microscopy allows the morphology and structure observation 
without the fragmentation of the targeted microparticles. CLSM was performed using a Zeiss confocal laser system (LSM 710) equipped with a diode laser (405 nm), Ar-laser (458, 488, $514 \mathrm{~nm}$ ), DPSS laser (diode pumped solid state e $561 \mathrm{~nm}$ ) and HeNe-laser (633 nm). The obtained powders were fluorescently stained with Red Congo $(40 \mu \mathrm{M})$, and the distribution of the bioactives into the powder matrix was observed using a Zeiss AxioObserver $\mathrm{Z} 1$ inverted microscope equipped with a 40x apochromatic objective (numerical aperture 1.4). Furthermore, the FS49, FS38, and FS15 filters were also used for the analysis. The 3D images were rendered, classified, and analyzed with the ZEN 2012 SP1 software (black edition).

\subsubsection{Powders Behavior in Simulated Digestion}

The simulated gastrointestinal digestion of the powders was performed according to Oancea et al. [16], at $37^{\circ} \mathrm{C}$ and $150 \mathrm{rpm}$ on an SI-300R orbital shaking incubator (Medline Scientific, Chalgrove, UK). The static model that simulates the digestion in the stomach was performed to measure the bioavailability of the anthocyanins and the antioxidant activity from the two variants of powders. The gastric digestion was performed for $2 \mathrm{~h}$ using simulated gastric fluid (SGF) that contained porcine pepsin $(40 \mathrm{mg} / \mathrm{mL}$ in $0.1 \mathrm{M} \mathrm{HCl})$ at a $\mathrm{pH}=2.00$. The intestinal digestion was performed using intestinal fluid (SIF) with $2 \mathrm{mg} / \mathrm{mL}$ pancreatin at $\mathrm{Ph}=5.3$. The release was calculated using Equation (3):

$$
\% \text { Release }=\frac{\text { initial concentration }}{\text { digested concentration }} \times 100
$$

\subsubsection{Statistical Analysis of Data}

The statistical analysis of data was performed using the Minitab 17 Statistics Software. The differences between the samples were assessed using the Tukey test with the One-way ANOVA method. All the experiments were completed in triplicates, and the results were expressed as average values with a standard deviation.

\section{Results}

\subsection{Eggplant Peel Extract Characterization}

Eggplant peels are rich in biologically active compounds, mainly in anthocyanins. In the present work, the bioactives from the eggplant peels were extracted using the UAE method, with ethanol as a solvent. This combination between the method, solvent, and acid had a $74.79 \%$ extraction yield. The obtained extract was analyzed in terms of phytochemical content and antioxidant activity, and the results are presented in Table 1 . The extract highlighted a TAC of $0.35 \pm 0.07 \mathrm{mg} \mathrm{C3G/g} \mathrm{dw}$, a TFC of $2.99 \pm 0.12 \mathrm{mg}$ CE $/ \mathrm{g} \mathrm{dw}$, and a TPC of $12.79 \pm 0.66 \mathrm{mg}$ GAE/g dw. The DPPH scavenging capacity of the extract presented $193.14 \pm 1.25 \mathrm{mM}$ TE/g dw.

Table 1. The phytochemical content of the eggplant peel extract.

\begin{tabular}{ccccc}
\hline $\begin{array}{c}\text { Phytochemical } \\
\text { Content }\end{array}$ & $\begin{array}{c}\text { TAC } \\
\text { mg D3G/g dw }\end{array}$ & $\begin{array}{c}\text { TFC } \\
\text { mg CE/g dw }\end{array}$ & $\begin{array}{c}\text { TPC } \\
\text { mg GAE/g dw }\end{array}$ & $\begin{array}{c}\text { Antioxidant Activity } \\
\text { mM TE/g dw }\end{array}$ \\
\hline Eggplant peel extract & $0.35 \pm 0.07$ & $2.99 \pm 0.12$ & $12.79 \pm 0.66$ & $193.14 \pm 1.25$ \\
\hline TAC = total anthocyanin content; TFC = total flavonoid content; TPC = total polyphenol content; D3G = delphinidin 3-O-glucoside; \\
CE = catehin equivalent; GAE = gallic acid equivalent; TE = trolox equivalent; dw = dry weight.
\end{tabular}

Hosseini et al. [17] presented a TAC of $0.43 \pm 1.24 \mathrm{mg} \mathrm{D3G/g} \mathrm{fw} \mathrm{and} \mathrm{a} \mathrm{TPC} \mathrm{of}$ $2.07 \pm 4.20 \mathrm{mg} \mathrm{GAE} / \mathrm{g} \mathrm{fw}$ after the conventional extraction of bioactives from eggplant peels using water/ethanol/acetic acid in a 50:48:2 ratio. On the contrary, Horincar et al. [18] reported higher TAC, TFC, and TPC values than ours after using acidified ethanol for the UAE extraction of the eggplant peels bioactives. However, the antioxidant activity on DPPH free radical reported by them presented lower values than our extract. Jung et al. [19] extracted the phenolics from different parts of eggplant and reported a TPC content of 
$55.19 \pm 1.30 \mathrm{mg} \mathrm{GAE} / \mathrm{g}$ extract and TFC of $6.19 \pm 0.28 \mathrm{mg}$ CE/g extract. The differences between our results and the other studies' results are due to the phytochemical variability from the raw material and extraction conditions. Though, the obtained data from Table 1 confirm that the eggplant peels are a rich source of biologically active compounds, especially anthocyanins.

\subsection{HPLC Analysis of the Anthocyanin}

In order to achieve the characterization of the eggplant anthocyanin profile a chromatographic analysis was performed by using the HPLC technique (Figure 2). The identification and the quantification of anthocyanin were made depending on the retention time and by comparison with the available standards and the data existing already in the literature.

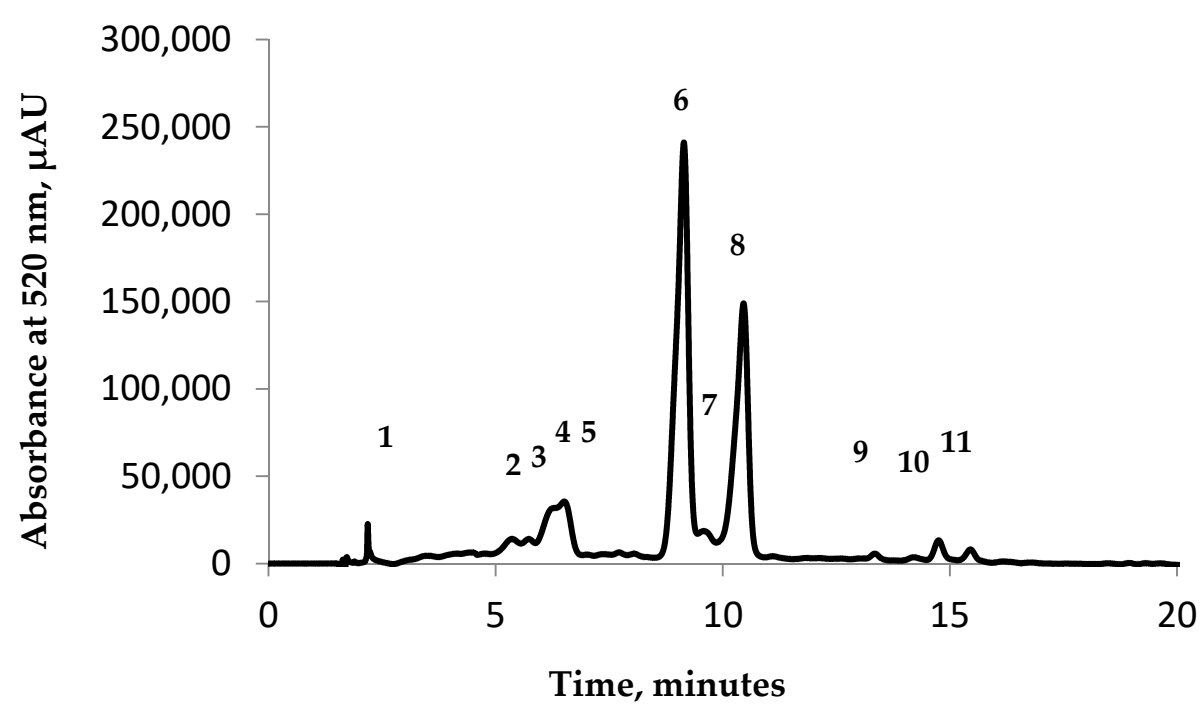

Figure 2. Chromatographic profile of eggplant peel extracts: Peak 1 -delphinidin 3-O-rutinoside5-glucoside; Peak 2-5: unidentified; Peak 6-delphinidin 3-O-glucoside; Peak 7-unidentified; Peak 8-delphinidin 3-O-rutinoside; Peak 9-unidentified; Peak 10-cyanidin 3-O-rutinoside; Peak 11-petunidin 3-O-rutinoside.

The anthocyanin identification was made at $520 \mathrm{~nm}$, and the chromatographic analysis revealed the presence of 11 compounds: delphinidin 3-O-rutinoside-5-glucoside (Peak 1), delphinidin 3-O-glucoside (Peak 6), delphinidin 3-O-rutinoside (Peak 8), cyanidin 3-Orutinoside (Peak 10), and petunidin 3-O-rutinoside (Peak 11), whereas peaks $2-5,7$, and 9 were unidentified.

The eggplant peel extract (Figure 2) revealed that delphinidin 3-O-glucoside is the major anthocyanin identified, having a concentration of $82.51 \%$. These results are in agreement with those obtained by Azuma et al. [20]. They managed to identify delphinidin 3-Orutinoside and nasunin as being the major compounds found in the eggplant extract. Delphinidin 3-O-rutinoside followed delphinidin 3-O-glucoside closely, with a concentration of $66.94 \%$. The other identified anthocyanin compounds varied in terms of concentration, such as: delphinidin 3-O-rutinoside-5-glucoside- $11.57 \%$, cyanidin 3-O-rutinoside- $5.08 \%$, and petunidin 3-O-rutinoside-2.14\%. In their studies, Ferarsa et al. [21], Dranca et al. [22], and Mauro et al. [23] managed to separate and identify only five anthocyanins from eggplant peel extracts. In our research conducted so far, we highlighted that the major anthocyanin found in eggplant is delphinidin 3-O-rutinoside. This study revealed a high concentration of delphinidin 3-O-glucoside. The difference between the two is explained by Mauro et al. [23], thereby passing to different stages of ripening, the delphinidin 3-Orutinoside concentration in different eggplant cultivars show a significant decrease. 


\subsection{Encapsulation Efficiency and Powders Characterization}

The encapsulation efficiency refers to the potential of wall material to entrap and hold the core material inside the capsule [24]. In our study, different wall material concentrations caused significant differences in the anthocyanin encapsulation efficiencies, as presented in Table $2(p<0.05)$. Thus, the encapsulation efficiency significantly increased with the polysaccharides concentration, ranging from $64.67 \pm 0.67 \%$ for V1 to $96.44 \pm 3.43 \%$ for V2 $(p<0.05)$. Our results are in agreement with other studies. Condurache et al. [15] reported encapsulation efficiencies of the eggplant peel anthocyanins in CMC, P, and WPI ranging from $69 \%$ to $77 \%$. In this study, an increase in the encapsulation efficiency was also observed with the increase of the CMC concentration.

Table 2. Characterization of the encapsulated eggplant peels extract.

\begin{tabular}{cccccc}
\hline $\begin{array}{c}\text { Phytochemical } \\
\text { Content }\end{array}$ & $\begin{array}{c}\text { TAC } \\
\mu \mathrm{g} \mathrm{D3G/g} \mathrm{dw}\end{array}$ & $\begin{array}{c}\text { TFC } \\
\text { mg CE/g dw }\end{array}$ & $\begin{array}{c}\text { TPC } \\
\text { mg GAE/g dw }\end{array}$ & $\begin{array}{c}\text { Antioxidant Activity } \\
\text { mM TE/g dw }\end{array}$ & $\begin{array}{c}\text { Encapsulation } \\
\text { Efficiency \% }\end{array}$ \\
\hline V1 & $50.41 \pm 2.13^{\mathrm{a}}$ & $1.53 \pm 0.06^{\mathrm{a}}$ & $8.03 \pm 0.18^{\mathrm{a}}$ & $41.96 \pm 0.28^{\mathrm{a}}$ & $64.67 \pm 0.67^{\mathrm{a}}$ \\
V2 & $94.94 \pm 7.94^{\mathrm{b}}$ & $1.64 \pm 0.14^{\mathrm{a}}$ & $7.22 \pm 0.18^{\mathrm{b}}$ & $36.60 \pm 0.83^{\mathrm{b}}$ & $96.44 \pm 3.43^{\mathrm{b}}$ \\
\hline
\end{tabular}

For each tested phytochemical and powder variant, values from the same column that do not share a letter are statistically different at $p<0.05$ based on the Tukey method and 95\% confidence. TAC—Total Anthocyanin Content; TFC—Total Flavonoid Content; TPC—Total Polyphenol Content.

Higher CMC and P concentrations also led to higher anthocyanin content entrapped in the powders. Thus, V2 presented a significantly higher TAC than V1 $(p<0.05)$. On the contrary, significantly higher TPC and antioxidant activity values were obtained for the variant with higher WPI concentration $(p<0.05)$. The TFC was not significantly different, regardless of the powder variant $(p>0.05)$. An opposite behavior was reported by Stanciuc et al. [25], who obtained higher polyphenol concentrations and antioxidant activities for higher pectin concentrations in grape skin bioactive-containing powders.

However, from Table 2, it can be observed that both powder variants showed high encapsulation efficiencies with high antioxidant activities. This leads us to conclude that the wall material combinations successfully encapsulated the phytochemicals from the eggplant peel extract.

\subsection{Storage Stability of the Powders}

The powders were stored at room temperature for 28 days and were characterized in terms of phytochemical content and antioxidant activity. The changes in TAC, TFC, TPC, and antioxidant activity of both powder variants during storage are shown in Figure 3.

The TAC and TFC of both powder variants did not significantly change during the 28 days of storage $(p>0.05)$. Instead, the TPC of V2 presented a significant increase $(p<0.05)$, while the TPC of V1 remained constant. Regarding the antioxidant activity, V1 showed significantly lower values after 28 days of storage, while V2 presented significantly higher values than the initial values $(p>0.05)$. Similar behavior was also reported by Moser et al. [26]. They suggested that the microencapsulation of grape juice combined with storage at low temperatures offered storage stability to the anthocyanins. On the contrary, Azarpazhooh et al. [27] reported a decrease in the TAC of the pomegranate peels bioactives microencapsulated powder as the period of storage increased.

However, from Figure 3, it can be observed that both variants showed low antioxidant activities and phytochemical content variation in time. This leads us to conclude that the used combination between CMC, P, and WPI successfully encapsulated the anthocyanins from eggplants peel extract, providing them good stability. 


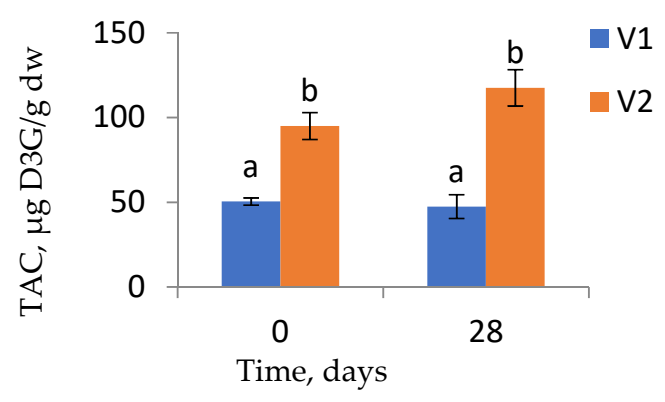

(a)

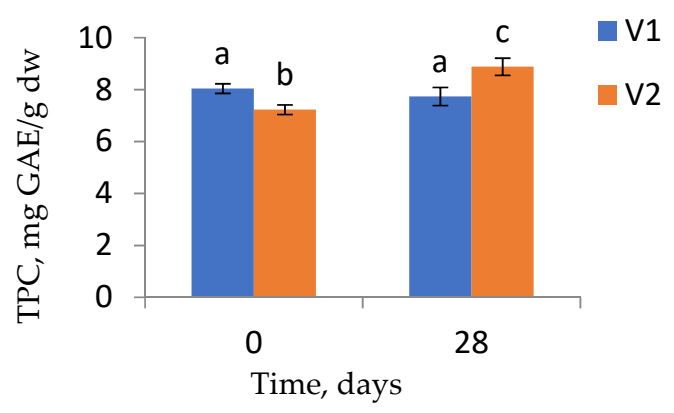

(c)

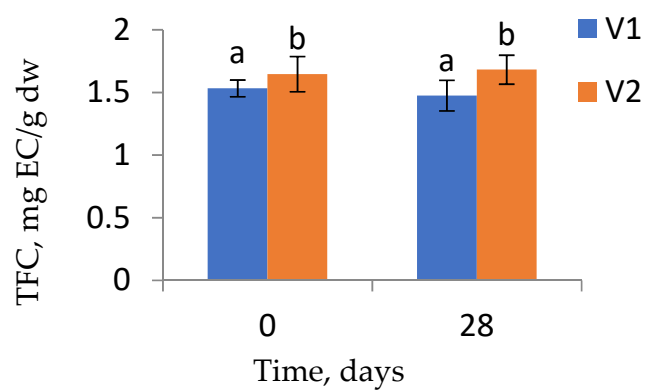

(b)

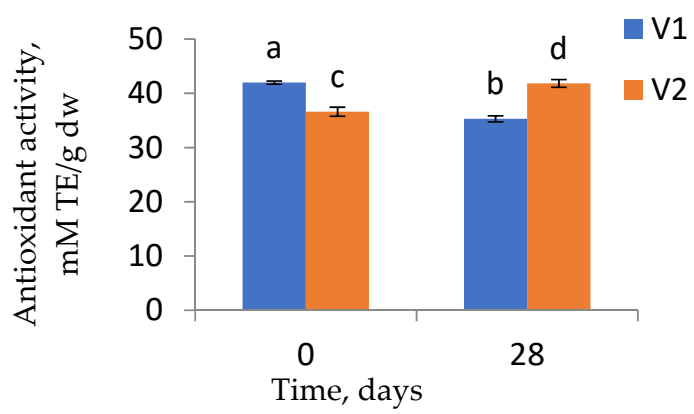

(d)

Figure 3. The TAC (a), TFC (b), TPC (c), and antioxidant activity (d) stability of the encapsulated powders after 28 days of storage at room temperature. For each tested phytochemical and powder variant, columns that do not share a letter are statistically different $p<0.05$. TAC—Total Anthocyanin Content; TFC—Total Flavonoid Content; TPC-Total Polyphenol Content.

\subsection{Morphological Structure of the Powders}

Confocal microscopy is an excellent tool to investigate the morphostructural features of microencapsulated powders. Using the LSM 710 point-by-point scanning equipment, with the DPSS (561 nm) and HeNe $(633 \mathrm{~nm})$ lasers and the corresponding filters (FS38 WF and FS15 WF, respectively), the samples were analyzed in both their native form (to observe the autofluorescence emission of the phytopigments from the eggplant extracts) as well as after staining of the samples with Congo Red, which has an affinity for the protein component of the microencapsulating matrix. Thus, the bioactives from the eggplant exocarp, by encapsulation, generated a digitiform, laced appearance in the V1 variant (Figure 4a) or compact irregular scales in the V2 variant (Figure 4b). Interestingly, the same plant extract displayed different autofluorescent properties depending on the proportion of biopolymers used for the microencapsulating matrix, probably due to the transient bonds created. The higher percentage of WPI in the V1 variant determined a frameshift of the emission to the range of 640-680 $\mathrm{nm}$, while in the presence of a matrix richer in polysaccharides (V2), the emission spectrum of the phytopigments in the extract appeared in the green-yellow domain (520-540 nm). Similar results were obtained by Chanoca et al. [28] in 2016 who used fluorescence lifetime microscopy to study the subcellular localization of anthocyanins in plant cells [28]. By labeling with Congo red (Figure $4 c, d$ ), the powders formed more or less homogeneous biofilms. In the WPI network (in red) predominant in the V1 sample matrix, a large diversity of bioactives (in green) was observed (Figure 4c). As the WPI content decreased and the content of carbohydrate polymers in the matrix increased, the powder became more hydrophilic, finer, and more homogeneous, and the fluorescent labeling with Congo red was weaker. 

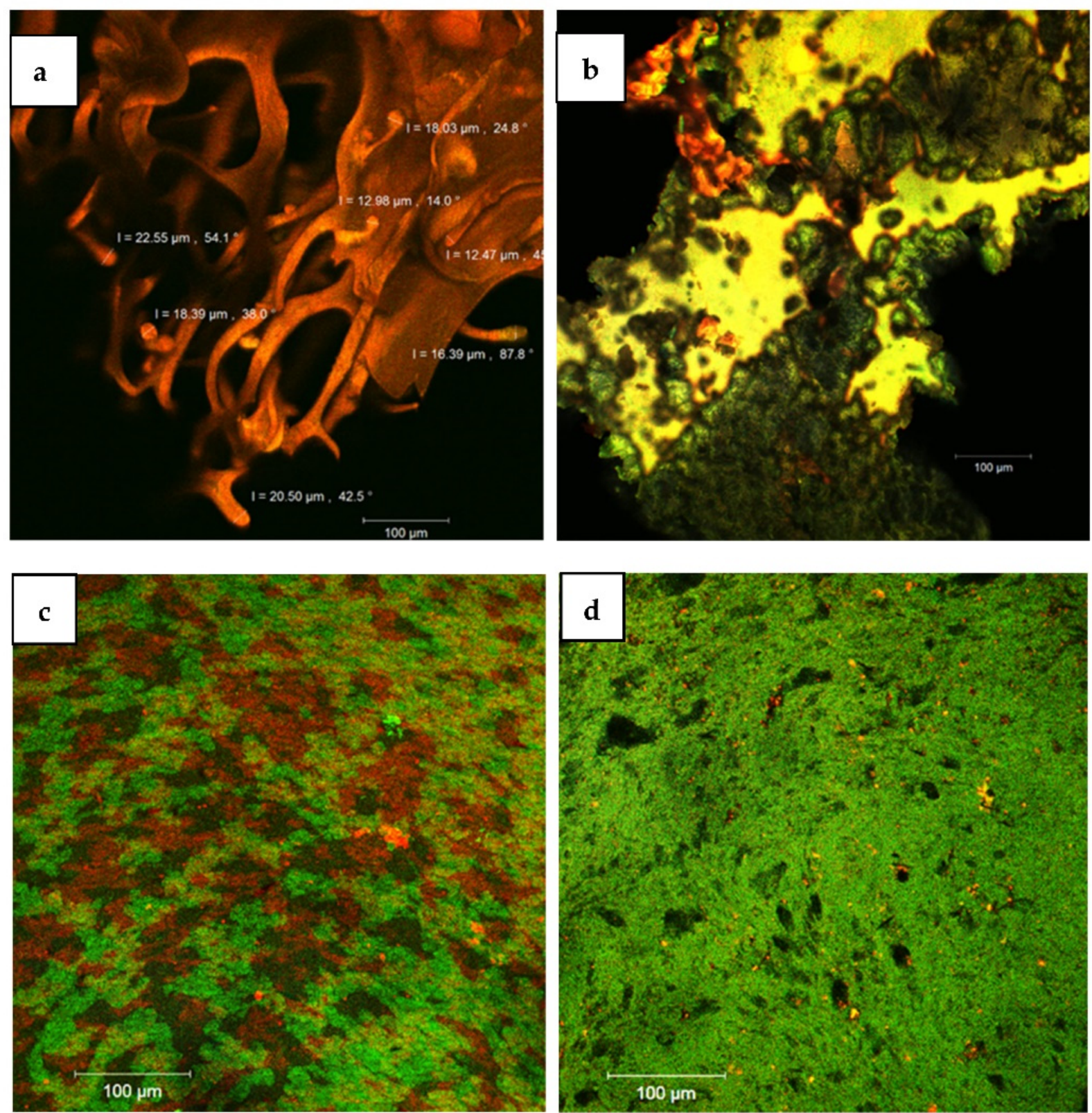

Figure 4. Confocal laser scanning images of the microencapsulated powders: V1 ((a)—native, (c)—stained) and V2 ((b) 一native, (d) —stained).

\subsection{Powders Behavior in Simulated Digestion}

The anthocyanins have the lowest bioavailability among polyphenols, with only $1-2 \%$ of them being absorbed by the human body. Their absorption is affected by the physicochemical conditions from the gastrointestinal tract, such as $\mathrm{pH}$, enzymes, and microbiota [29]. The combination between a top-down method such as gelation and a bottom-up method such as freeze-drying can represent a solution to assure an intelligent delivery system for the eggplant peel anthocyanins.

In our study, the encapsulated powders' behavior was studied under simulated gastric and intestinal conditions. The results obtained for the in vitro digestibility in simulated gastric fluid (SGF) showed that the encapsulation methods and the selected coating materials presented a protective effect on the anthocyanin release. In Figure 5a, we observed a remarkable anthocyanin content stability, with only $3 \%$ and $7 \%$ release for $\mathrm{V} 1$ and V2, respectively, after $120 \mathrm{~min}$ of gastric digestion. After the intestinal fluid was 
added, an accelerated anthocyanin release from the matrices was observed (Figure $5 b$ ). Thus, the anthocyanins from V1 completely released after only $60 \mathrm{~min}$. For V2 instead, the anthocyanins started to gradually release in time. Thus, after $30 \mathrm{~min}$ of digestion, half of the anthocyanins were released from the matrix, reaching complete release after $120 \mathrm{~min}$ of digestion. It can be noticed a higher anthocyanin protective effect by the matrix containing higher $\mathrm{CMCNa}$ and P concentration.

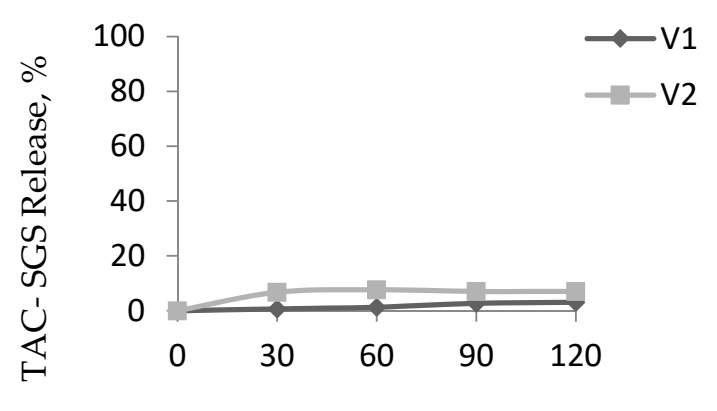

Time, $\min$

(a)

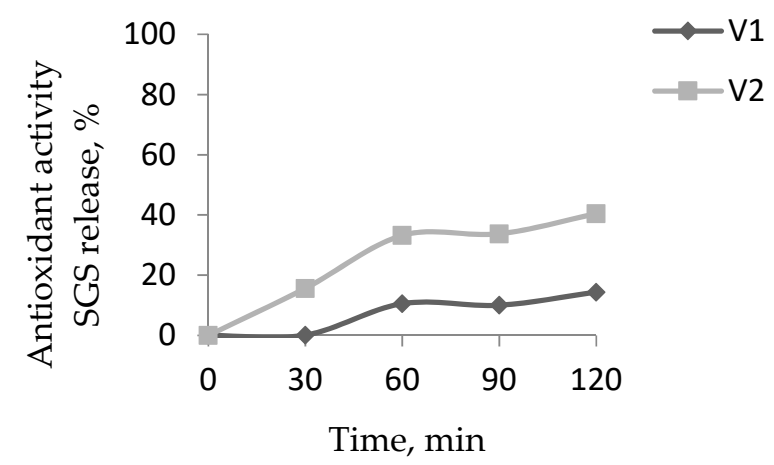

(c)

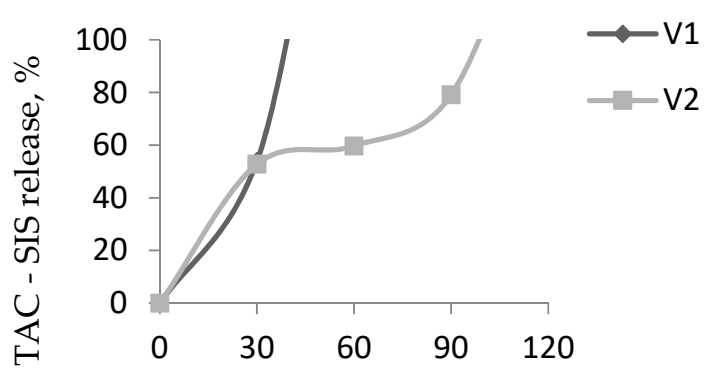

Time, $\min$

(b)

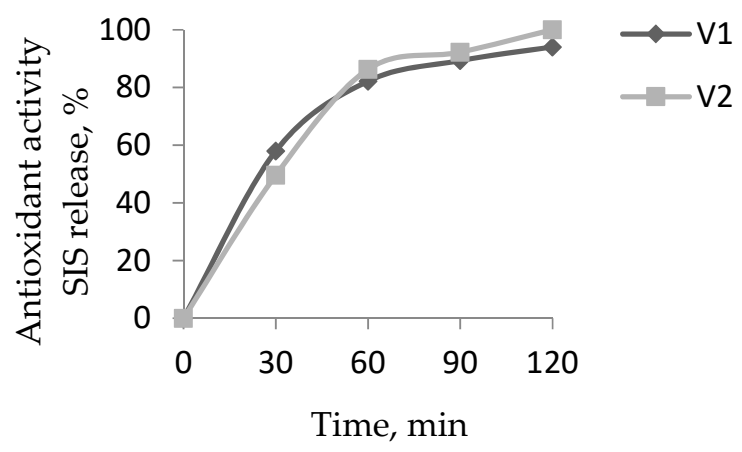

(d)

Figure 5. In vitro digestibility of encapsulated anthocyanin and antioxidant activity in simulated gastric fluid (a,c) and simulated intestinal fluid $(\mathbf{b}, \mathbf{d})$.

Condurache et al. [15] reported a high protective effect of the anthocyanins from eggplant peels encapsulated with proteins and polymers, with a maximum of $42 \%$ intestinal release. Instead, Huang and Zhou [30] reported that a complete release of the encapsulated anthocyanins from black rice occurred after 20 min of intestinal digestion.

In terms of antioxidant activity, there is a release of up to $14 \%$ for V1 and $40 \%$ for V2 after 120 min of simulated gastric digestion (Figure 5c). If in the anthocyanin's case, their complete release in simulated intestinal digestion took place after only $60 \mathrm{~min}$ for V1, in the case of antioxidant activity, a gradual release is observed for both variants (Figure 5d). Thereby, a $50 \%$ release is observed for both variants after the first $30 \mathrm{~min}$ of simulated intestinal digestion. Afterward, the release took place more slowly, reaching full release after 120 min of digestion. These results may be explained by the phenolic acids formed during the degradation of the anthocyanins in intestinal digestion [31].

\section{Conclusions}

This study focused on the obtaining of functional ingredients for food or nutraceuticals applications by the extraction and encapsulation of phenolic compounds from eggplant peels, mainly on the anthocyanins. Thereby, the anthocyanins were extracted using the ultrasound-assisted extraction method and phytochemically characterized. The major anthocyanin from the extract is delphinidin 3-O-glucoside. Further, the present study aimed to compare the impact of the two encapsulation matrices on the stability and controlled release of the anthocyanins. Thus, the gelation technique combined with the freeze-drying 
technique was used, and the wall materials tested in this study were the $\mathrm{CMCNa}, \mathrm{P}$, and WPI in different concentrations. It has been demonstrated that higher concentrations of $\mathrm{CMCNa}$ and $\mathrm{P}$ in the encapsulation matrix resulted in higher anthocyanin retention, encapsulation efficiency, and storage stability. The confocal microscopy revealed a digitiform, laced appearance in the V1 and compact irregular scales in the V2 generated by the eggplant peels' bioactives. As the content of polysaccharides increased in the matrix, the powder became more hydrophilic and homogeneous. The in vitro digestion study indicated that each type of matrix exhibited a different protection mechanism for the anthocyanin and the antioxidant activity of the encapsulated powders. A higher polysaccharide concentration in the matrix provides high anthocyanin stability in the gastric system and a gradual release in the intestinal system, which can lead to their better absorption.

Our results can be used in formulating new functional foods with high value added. In this regard, more research will be further addressed.

Author Contributions: Conceptualization, N.-N.C.; methodology, N.-N.C.; software, N.-N.C., E.E., V.B., and M.T.; validation, N.S. and G.R.; formal analysis, N.-N.C., E.E., V.B., and M.T.; investigation, N.-N.C.; resources, G.-E.B., G.R., and C.C.; data curation, N.-N.C.; writing-original draft preparation, N.-N.C.; writing-review and editing, G.R., C.C., and N.S.; visualization, G.-E.B.; supervision, N.S.; project administration, G.-E.B.; funding acquisition, G.-E.B. and G.R. All authors have read and agreed to the published version of the manuscript.

Funding: This work was supported by project number PN-III-P1-1.2-PCCDI-2017-0569-PRO-SPER (10PCCI) within the PNCDI program.

Institutional Review Board Statement: Not applicable.

Informed Consent Statement: Not applicable.

Data Availability Statement: The data that support the findings of this study are available from the corresponding author (G.R.) upon reasonable request.

Acknowledgments: This work was supported by the Integrated Center for Research, Expertise and Technological Transfer in Food Industry (Bioaliment TehnIA), which provided technical support.

Conflicts of Interest: The authors declare no conflict of interest.

\section{References}

1. Nayak, A.; Bhushan, B. An overview of the recent trends on the waste valorization techniques for food wastes. J. Environ. Manag. 2019, 233, 352-370. [CrossRef]

2. Galanakis, C.M. Food waste recovery: Prospects and opportunities. In Sustainable Food Systems from Agriculture to Industry. Improving Production and Processing; Galanakis, C.M., Ed.; Academic Press: Cambridge, MA, USA, 2018; pp. 401-419.

3. Shahidi, F.; Ambigaipalan, P. Phenolics and polyphenolics in foods, beverages and spices: Antioxidant activity and health effects-A review. J. Funct. Foods 2015, 18, 820-897. [CrossRef]

4. Baenas, N.; Abellán, A.; Rivera, S.; Moreno, D.A.; García-Viguera, C.; Domínguez-Perles, R. Foods and supplements. In Polyphenols: Properties, Recovery, and Applications; Galanakis, C.M., Ed.; Woodhead Publishing: Cambridge, MA, USA, 2018; pp. 327-362.

5. Concellón, A.; Añon, M.C.; Chaves, A.R. Effect of low temperature storage on physical and physiological characteristics of eggplant fruit (Solanum melongena L.). LWT 2007, 40, 389-396. [CrossRef]

6. Burton-Freeman, B.; Sandhu, A.; Edirisinghe, I. Anthocyanins. In Nutraceuticals. Efficacy, Safety and Toxicity; Gupta, R.C., Ed.; Academic Press: Cambridge, MA, USA, 2016; pp. 489-500.

7. Rodriguez-Amaya, D.B. Update on natural food pigments-A mini-review on carotenoids, anthocyanins, and betalains. Food Res. Int. 2019, 124, 200-205. [CrossRef]

8. Xiong, J.; Chan, Y.H.; Rathinasabapathy, T.; Grace, M.H.; Komarnytsky, S.; Lila, M.A. Enhanced stability of berry pomace polyphenols delivered in protein-polyphenol aggregate particles to an in vitro gastrointestinal digestion model. Food Chem. 2020, 331, 127279. [CrossRef]

9. Celli, G.B.; Ghanem, A.; Brooks, M.S.-L. Bioactive Encapsulated Powders for Functional Foods-A Review of Methods and Current Limitations. Food Bioprocess Technol. 2015, 8, 1825-1837. [CrossRef]

10. Condurache, N.-N.; Croitoru, C.; Enachi, E.; Bahrim, G.-E.; Stănciuc, N.; Râpeanu, G. Eggplant Peels as a Valuable Source of Anthocyanins: Extraction, Thermal Stability and Biological Activities. Plants 2021, 10, 577. [CrossRef] [PubMed]

11. Turturică, M.; Stănciuc, N.; Bahrim, G.; Râpeanu, G. Effect of thermal treatment on phenolic compounds from plum (prunus domestica) extracts—A kinetic study. J. Food Eng. 2016, 171, 200-207. [CrossRef] 
12. Swer, T.L.; Mukhim, C.; Bashir, K.; Chauhan, K. Optimization of enzyme aided extraction of anthocyanins from Prunus nepalensis L. LWT 2018, 91, 382-390. [CrossRef]

13. Serrano-Cruz, M.R.; Villanueva-Carvajal, A.; Morales-Rosales, E.J.; Dávila, J.F.R.; Dominguez-Lopez, A. Controlled release and antioxidant activity of Roselle (Hibiscus sabdariffa L.) extract encapsulated in mixtures of carboxymethyl cellulose, whey protein, and pectin. LWT 2013, 50, 554-561. [CrossRef]

14. Batista, R.A.; Espitia, P.J.P.; Quintans, J.D.S.S.; Freitas, M.M.; Cerqueira, M.Â.; Teixeira, J.A.; Cardoso, J.C. Hydrogel as an alternative structure for food packaging systems. Carbohydr. Polym. 2019, 205, 106-116. [CrossRef]

15. Condurache, N.N.; Aprodu, I.; Crăciunescu, O.; Tatia, R.; Horincar, G.; Barbu, V.; Enachi, E.; Râpeanu, G.; Bahrim, G.E.; Oancea, A.; et al. Probing the Functionality of Bioactives from Eggplant Peel Extracts Through Extraction and Microencapsulation in Different Polymers and Whey Protein Hydrolysates. Food Bioprocess Technol. 2019, 12, 1316-1329. [CrossRef]

16. Oancea, A.-M.; Hasan, M.; Vasile, A.M.; Barbu, V.; Enachi, E.; Bahrim, G.; Râpeanu, G.; Silvi, S.; Stănciuc, N. Functional evaluation of microencapsulated anthocyanins from sour cherries skins extract in whey proteins isolate. LWT 2018, 95, 129-134. [CrossRef]

17. Hosseini, S.; Gharachorloo, M.; Ghiassi-Tarzi, B.; Ghavami, M. Evaluation the Organic Acids Ability for Extraction of Anthocyanins and Phenolic Compounds from different sources and Their Degradation Kinetics during Cold Storage. Pol. J. Food Nutr. Sci. 2016, 66, 261-269. [CrossRef]

18. Horincar, G.; Enachi, E.; Stănciuc, N.; Râpeanu, G.; de Jos, D.; University of Galati. Extraction and characterization of bioactive compounds from eggplant peel using ultrasound-assisted extraction. Ann. Univ. Dunarea Jos Galati Fascicle VI Food Technol. 2019, 43, 40-53. [CrossRef]

19. Jung, E.J.; Bae, M.S.; Eun-Kyung, J.; Jo, Y.J.; Lee, S.C. Antioxidant activity of different parts of eggplant. Res. J. Med. Plant 2011, 5, 4610-4615. [CrossRef]

20. Azuma, K.; Ohyama, A.; Ippoushi, K.; Ichiyanagi, T.; Takeuchi, A.; Saito, T.; Fukuoka, H. Structures and Antioxidant Activity of Anthocyanins in Many Accessions of Eggplant and Its Related Species. J. Agric. Food Chem. 2008, 56, 10154-10159. [CrossRef] [PubMed]

21. Ferarsa, S.; Zhang, W.; Moulai-Mostefa, N.; Ding, L.; Jaffrin, M.Y.; Grimi, N. Recovery of anthocyanins and other phenolic compounds from purple eggplant peels and pulps using ultrasonic-assisted extraction. Food Bioprod. Process. 2018, 109, 19-28. [CrossRef]

22. Dranca, F.; Oroian, M. Optimization of ultrasound-assisted extraction of total monomeric anthocyanin (TMA) and total phenolic content (TPC) from eggplant (Solanum melongena L.) peel. Ultrason. Sonochem. 2016, 31, 637-646. [CrossRef]

23. Mauro, R.P.; Agnello, M.; Rizzo, V.; Graziani, G.; Fogliano, V.; Leonardi, C.; Giuffrida, F. Recovery of eggplant field waste as a source of phytochemicals. Sci. Hortic. 2020, 261, 109023. [CrossRef]

24. Stoll, L.; Costa, T.M.H.; Jablonski, A.; Flores, S.; Rios, A.D.O. Microencapsulation of Anthocyanins with Different Wall Materials and Its Application in Active Biodegradable Films. Food Bioprocess Technol. 2016, 9, 172-181. [CrossRef]

25. Stănciuc, N.; Turturică, M.; Oancea, A.M.; Barbu, V.; Ioniţă, E.; Aprodu, I.; Râpeanu, G. Microencapsulation of Anthocyanins from Grape Skins by Whey Protein Isolates and Different Polymers. Food Bioprocess Technol. 2017, 10, 1715-1726. [CrossRef]

26. Moser, P.; Telis, V.R.N.; Neves, N.D.A.; García-Romero, E.; Gómez-Alonso, S.; Hermosín-Gutiérrez, I. Storage stability of phenolic compounds in powdered BRS Violeta grape juice microencapsulated with protein and maltodextrin blends. Food Chem. 2017, 214, 308-318. [CrossRef] [PubMed]

27. Azarpazhooh, E.; Sharayei, P.; Zomorodi, S.; Ramaswamy, H.S. Physicochemical and Phytochemical Characterization and Storage Stability of Freeze-dried Encapsulated Pomegranate Peel Anthocyanin and In Vitro Evaluation of Its Antioxidant Activity. Food Bioprocess Technol. 2018, 12, 199-210. [CrossRef]

28. Chanoca, A.; Burkel, B.; Kovinich, N.; Grotewold, E.; Eliceiri, K.W.; Otegui, M.S. Using fluorescence lifetime microscopy to study the subcellular localization of anthocyanins. Plant J. 2016, 88, 895-903. [CrossRef] [PubMed]

29. Tarone, A.G.; Cazarin, C.B.B.; Junior, M.R.M. Anthocyanins: New techniques and challenges in microencapsulation. Food Res. Int. 2020, 133, 109092. [CrossRef]

30. Huang, Y.; Zhou, W. Microencapsulation of anthocyanins through two-step emulsification and release characteristics during in vitro digestion. Food Chem. 2019, 278, 357-363. [CrossRef]

31. Kim, I.; Moon, J.K.; Hur, S.J.; Lee, J. Structural changes in mulberry (Morus Microphylla. Buckl) and chokeberry (Aronia melanocarpa) anthocyanins during simulated in vitro human digestion. Food Chem. 2020, 318, 126449. [CrossRef] 